\title{
IDENTIDADES LINGÜÍSTICAS \\ E POLÍTICA EN EUROPA
}

Peter A. Kraus

Helsingin Yliopisto 



\section{A POLÍTICA DA LINGUA NA EUROPA DE HOXE: OS TEMAS DE DEBATE}

Como aprendemos nas aulas de Xeografía e Historia, o mapamundi moderno componse de unidades discretas, todas as cales reflicten basicamente a mesma lóxica institucional: a da formación dos estados-nación. Nos mapas políticos cada unidade representa unha entidade que é ao tempo diferenciada e homoxénea, á que se lle asigna por dereito unha cor de seu, e que, alén diso, ten un nome único. Tales mapas pódense tomar como proba inicial do modo de funcionamento do "nacionalismo metodolóxico»: dado que desde a etapa escolar nos familiarizamos cunha perspectiva segundo a cal se estrutura a realidade social e política en espazos nacionais, as formas «banais» de nacionalismo tórnanse nun fenómeno omnipresente, quer no sistema educativo, quer no eido deportivo ou nos partes meteorolóxicos (Billig 1995). Ora ben, o que probablemente sexa máis pertinente para o noso debate radica en que, no mapa político da Europa contemporánea, en case todos os casos o nome dunha unidade vai asociado directamente a unha lingua, a lingua maioritaria do Estado, trazo este que distingue a Europa da meirande parte das demais rexións do mundo e que amosa a forte influencia que exerce o nacionalismo lingüístico na configuración de Europa tal e como a coñecemos hoxe. En canto cidadáns europeos medios interiorizamos que en "Francia» se fala francés; en «Suecia», sueco; en «Romanía», romanés, etc. É longa a lista dos casos similares e existen poucas excepcións ao patrón xeral. No contexto europeo, a falta de correspondencia entre lingua e Estado tende a revelar algunhas peculiaridades ou mesmo «anomalías», como parece demostrar un caso como o de Bélxica, país exposto a un prolongado conflito lingüístico e sometido a fortes presións centrífugas.

Cando pasamos a considerar os principais problemas que afectan a política da lingua na Europa de hoxe, a situación, a grandes liñas, poderíase esbozar así: 
segue presente o herdo deixado por circunstancias anteriores, que interactúan coas dificultades que se manifestan nas circunstancias actuais. Con "herdo das circunstancias anteriores» refírome aos agravios lingüísticos que van asociados á formación do sistema de estados-nación en Europa; en efecto, existe un número significativo de grupos minoritarios, como os galeses ou os cataláns, que se consideran vítimas deste proceso e cuxos membros reclaman que se recoñeza a súa identidade lingüística particular, durante moito tempo marxinada polas nacións dominantes. $\mathrm{Na}$ Europa oriental, a regulación da condición das minorías figura desde 1989 entre os puntos prioritarios que hai que tratar no debate político; ao mesmo tempo, existen grupos indíxenas — por exemplo, os samique se poden considerar casos especiais no mapa das minorías, posto que non «encaixan» moi ben no patrón nacional de organización política.

Aínda que o herdo das circunstancias de antes segue a ser patente en toda Europa, tamén nos vemos obrigados a tentar darlle resposta a unha pregunta de hoxe, a de como tratar as minorías inmigrantes, cuxa integración ten unha dimensión lingüística evidente. É máis, aquelas maiorías que están en contacto con esta "nova» heteroxeneidade parecen tender, cada vez máis, a apoiar as tendencias políticas que reafirman a súa identidade lingüística fronte ás minorías emigrantes; e, así, na meirande parte das democracias europeas que contan cunha fracción significativa de poboacións estranxeiras no seu seo, insístese moito na adquisición da lingua nacional no contexto da regulación do acceso á cidadanía ${ }^{1}$. Nalgúns casos esta tendencia tamén se pode asociar, en termos máis xerais, ás consecuencias lingüísticas da europeización, proceso que está a xerar un debate arredor da cuestión de se, nunha unidade política europea que se vai desenvolvendo, as comunicacións públicas deberían basearse nunha fórmula plurilingüe ou máis ben no «inglés europeo». Ao mesmo tempo, o triunfo da lingua de Shakespeare como lingua franca europea de facto vincula a europeización á dinámica global da comunicación e suscita claras reaccións nacionalistas en comunidades que falan linguas que durante moito tempo se consideraran «dominantes».

Os laboratorios máis interesantes para observar a interacción que se dá entre o antigo e o novo probablemente sexan cidades coma Bruxelas, Barcelona e, malia que polo de agora en menor medida, Helsinqui, onde as capas de diferenciación lin-

${ }^{1}$ Véxase unha panorámica xeral en Hogan-Brun, Mar-Molinero e Stevenson (2009). 
güística introducida polos inmigrantes nas últimas décadas se engaden a un plurilingüismo «endóxeno» de raizame histórica. En tales escenarios sociolingüísticos é lexítimo preguntármonos se estamos a falar dun mosaico posmoderno de identidades entrecruzadas que os membros dos diversos grupos poden escoller e artellar con maior ou menor liberdade ou se, pola contra, estamos a presenciar o nacemento dun «novo medievalismo», pois a volta á Idade Media implicaría que os patróns de estratificación e diferenciación lingüística tenderían a superpoñerse de novo, como nos tempos previos á modernidade, polo menos cando examinamos os dous extremos do espectro social. Así, os segmentos superiores do persoal das empresas transnacionais, os expertos en tecnoloxías da información e os banqueiros, xunto cos traballadores dos centros de investigación ou das universidades, cada vez usan máis o inglés como medio de comunicación básico; pola contra, no outro extremo da escala atopamos o groso dos inmigrantes procedentes do norte de África, o sur de Asia, Turquía e outras rexións do planeta, que seguen a usar a súa lingua materna e, deste xeito, outórganlles a linguas como o árabe ou o turco un peso significativo na escena sociolingüística da Europa occidental, polo que as linguas autóctonas tradicionais fican, en diversos graos, «encaixadas» entre as capas lingüísticas «exóxenas» novas. Esta tendencia «neomedieval», que os membros das clases medias locais adoitan observar con preocupación, constituiría a pegada que a sucesiva desconexión de territorialidade, control político e identidade cultural (Sassen 2006) vai deixando na configuración sociolingüística dos nosos espazos urbanos.

Podemos, abofé, entender a identidade lingüística e o uso da lingua como indicadores clave das irresistibles transformacións socioculturais e sociopolíticas: despois dun longo período en que se vinculou a integración política coa loita pola homoxeneidade cultural e lingüística, parece que as cousas volven moverse e, máis aínda, as tendencias que bosquexo apuntan a unha repolitización das cuestións lingüísticas en toda Europa.

\section{A LINGUA E A FORMACIÓN DOS ESTADOS-NACIÓN}

Segundo os cálculos dos lingüistas, na Europa actual fálanse arredor de 225 linguas autóctonas, cifra que non resulta espectacular se a comparamos co que ocorre en África e Asia, onde temos máis de 2000 idiomas en cada caso, ou nas 
Américas, onde o número de linguas nativas anda polo millar. No entanto, un aspecto fundamental que distingue Europa doutras rexións do mundo é a preeminencia do factor lingüístico na estruturación política do continente. En efecto, a configuración da Europa moderna estivo ligada dun xeito substancial á aparición dun sistema de estados-nación discretos e, no decorrer deste proceso, as fronteiras lingüísticas e políticas pasaron a ser cada vez máis intercambiables (Rokkan 1999: 170-90). Os estándares vernáculos non só pasaron a ser empregados como ferramentas de comunicación de masas, senón que tamén se lles conferiu unha función emblemática en canto símbolos da identidade institucional dun ou doutro estado-nación concreto. Así, o concepto de idioma nacional pode entenderse basicamente como concepto europeo, que lles outorgou aos factores lingüísticos un gran peso nas mobilización nacionalistas que son características da modernidade europea ${ }^{2}$; e, deste xeito, a formación dos estadosnación da Europa moderna foi a formación duns espazos en que as culturas políticas e lingüísticas se superpoñen en boa medida.

Canda a relixión, a lingua foi o principal elemento da puxa pola estandarización cultural en que se fundamenta a dinámica da construción nacional. Co auxe do absolutismo, os estados europeos deron en vincular a afirmación da súa soberanía nacional á loita pola creación dun dominio de goberno culturalmente homoxéneo e, neste sentido, a adopción do principio cuius regio, eius religio logo tivo a súa continuación lóxica na aplicación da norma cuius regio, eius lingua. Visto na perspectiva histórica, o proceso de estandarización lingüística seguiu inicialmente un sentido «descendente»: no fin de contas, os pioneiros da formación estatal, como Francia, pretenderon establecer estándares lingüísticos uniformes en todo o seu territorio por razóns de eficacia administrativa, obxectivo que claramente se correspondía cos imperativos da racionalización económica e burocrática que Max Weber analizou polo miúdo na súa socioloxía do Estado (1980: 815-37). Un primeiro exemplo das prioridades da política lingüística absolutista é a Ordonnance de Villers-Cotterêts (1539), pola que se prescribiu que toda a comunicación escrita de índole legal que se emitise no Estado francés había ir nesta lingua (Jacob e Gordon 1985: 111-2). Co tempo, a ten-

${ }^{2}$ Véxase Coulmas (1985: 29-31); en Burke (2004) pódese atopar unha descrición dos usos lingüísticos sociais e institucionais en Europa antes da época culminante do nacionalismo. 
dencia a crear un marco monolingüe de comunicación entre as autoridades públicas e o pobo que estas gobernaban volveuse un trazo común da modernización política en Europa, tendencia que se foi deixando sentir con aínda máis intensidade, ata o extremo de que a lingua deu en ser concibida como marcador de identidade que podía usarse para outros fins semellantes, como a relixión, e servir a causa "protonacionalista" de reforzo dos vencellos existentes entre estados, gobernantes e súbditos. Así, na área escandinava achamos, xa nunha etapa temperá, un alto grao de conexión entre os factores relixiosos e os lingüísticos na configuración das identidades colectivas: en efecto, como consecuencia do establecemento das igrexas estatais luteranas, as linguas vernáculas pasaron a ser o medio vehicular das cerimonias relixiosas e da instrución escolar, o cal contribuíu á creación dun escenario en que se podían forxar as "culturas nacionais» dun modo menos conflitivo que na Europa meridional e central, onde o latín mantiña unha posición de preeminencia por mor da forza indómita do catolicismo.

No camiño da gradual transición cara á democracia que comezou coa Revolución francesa, o nacionalismo lingüístico cobrou pulo en canto fenómeno ascendente, pois, logo de servir durante séculos como instrumento de penetración administrativa, o idioma francés era enxalzado agora no discurso dos xacobinos, que vían nel o símbolo da razón universal e un ben que permitía a emancipación colectiva. Á derradeira, o celo revolucionario non fixo máis que aumentar a presión exercida sobre os falantes das distintas linguas vernáculas (como o éuscaro, o bretón e os dialectos occitanos), que aínda se usaban amplamente nas periferias ben entrado o século XIX, para que abrazasen o francés como «lingua materna», dado que daquela non só se consideraba que os idiomas rexionais representaban unha rémora para a consolidación das estruturas do Estado uniforme, senón que ademais se sospeitaba deles por acaso apoiaren fins antirrepublicanos (Maas 1989: 39-41). Por tal motivo, no caso francés o patrón republicano de integración lingüística supuxo a continuidade do legado absolutista, malia que certamente que desde outra perspectiva. En troques, noutras zonas de Europa, ante a activación da dimensión ascendente das políticas da lingua puxéronse en cuestión con contundencia os antigos fundamentos da hexemonía cultural que estaban presentes en estruturas estatais dadas, tendencia que se tornou particularmente virulenta en Europa oriental: así, desde as terras checas ata a Ucraína, desde o Báltico ata os Balcáns, os movementos nacionalistas asignáronlles 
á defensa e á vitalización das linguas vernáculas un lugar central na súa política. A idea de que a lingua expresaba a "alma» do pobo e de que todas elas tiñan igual dignidade, con independencia da condición «inferior» ou «superior» das culturas que representaban, pasou a ser un motivo recorrente das mobilizacións nacionalistas (Hroch 1985). Para aqueles que abrazaron tal idea, as linguas vernáculas constituían nada menos que o modelo mestre a partir do cal artellar a loita contra a alienación nacional e a revolta colectiva contra un dominio imperialista que, como tal, se expresaba en turco, ruso ou alemán.

A grandes liñas, atopamos algún tipo de combinación de dinámicas descendentes e ascendentes en case todos os contextos en que a lingua pasou a ser un elemento político destacado en Europa. Os estados territoriais europeos historicamente máis consolidados $\longrightarrow$, en termos xerais, de meirande extensión—, occidentais a maioría deles, tenderon a seguir a estratexia do nacionalismo «oficial»" que tiña como obxectivo acadar un maior grao de lexitimidade política obrigando as minorías á asimilación lingüística. Na metade oriental do continente, porén, os movementos constituídos baixo a bandeira da emancipación lingüística fixeron, co tempo, que se desencadease a crise dos antigos imperios e abríronlle as portas á independencia nacional dun gran número de países; no entanto, ha de advertirse que, en xeral, a creación destes novos estados non implicou que as súas elites adoptasen unha actitude ante a diversidade lingüística máis benigna cá dos anteriores gobernantes imperiais dos mesmos territorios. Por toda Europa a mobilización social que contribuíu á converxencia da procura da soberanía do pobo e os obxectivos nacionalistas, nos séculos XIX e XX, reforzou o peso das linguas «nacionais» en canto idiomas que se consideraba que representaban unhas identidades nacionais dadas (Deutsch 1966) e, así, os estados-nación transformáronse nos «contedores» institucionais básicos (Giddens 1985) da política democrática nuns procesos que, en boa medida, discorreron en paralelo á difusión das linguas vernáculas estandarizadas. Con todo, recoñecer tal paralelismo non debería levarnos a participar de «grandiosas narrativas nacionais» segundo as cales existen vencellos perennes que ligan unha nación coa «súa» lingua e unha lingua coa «súa» nación. Máis aínda, tampouco resulta recomendable que a percepción dunha tendencia histórica se converta nunha fonte da que tirar conclusións normativas aplicables ao presente, porque a política da estan-

\footnotetext{
${ }^{3}$ En Anderson (1991: 83-111) coméntase este concepto polo miúdo.
} 
darización cultural e lingüística xa tivo un alto custo para aqueles grupos aos que se lles impuxeron os estándares das nacións nominais, grupos que se converteron en minorías dotadas dunha marxe de manobra substancialmente limitada para accederen á autodeterminación colectiva.

Como amosa Eisenstadt (1999) de xeito contundente, a dimensión xacobina deixou unha forte pegada na arquitectura institucional da modernidade. No tocante á articulación da identidade lingüística, esa pegada comportou unha intensa procura da homoxeneización. Desde a perspectiva xacobina, a diversidade lingüística ten o risco de propiciar a división da sociedade política e a civil e, xa que logo, debe ser superada polo ben do conxunto nacional; ou, en todo caso, as adscricións lingüísticas que puidesen dar lugar a reivindicacións de recoñecemento han de quedar suxeitas a un estilo control estatal. Os estados europeos modernos máis próximos a nós seguiron esta liña xacobina e, dese xeito, a medida que se convertían en máquinas de asimilación lingüística, loitaron por acadar unha homoxeneidade cultural tocante tanto ao reforzo da súa capacidade administrativa como á fusión dos patróns de lexitimación cultural e política. Na súa versión belixerante, o Estado-nación europeo parece ser un Estado "glotófago» (Laponce 1987: 201), un Estado que devora as linguas minoritarias para establecer un réxime estritamente monolingüe no ámbito público.

Ante este panorama, poida que haxa que admitir a desacougante posibilidade de que a dinámica histórica da democratización incite a prácticas de homoxeneización que mal se diferencian da limpeza étnica (Mann 2005). A teoría democrática tende a dar por sentado que os principios democráticos se despregan en espazos lingüisticamente integrados, mais a actual interacción que se dá entre democratización e integración ou asimilación lingüística na Europa moderna merecería unha análise máis polo miúdo. Abofé, xa case resulta tópico asociar o ascenso da democracia representativa co desenvolvemento da esfera pública, na cal os cidadáns ilustrados manteñen un debate aberto sobre cuestións de interese xeral (Habermas 1990). No entanto, máis unha vez, ante este panorama non se debería pasar por alto que, no contexto institucional da modernidade europea, a formación das esferas públicas seguiu a lóxica da construción do estado-nación ${ }^{4}$ e, así,

${ }^{4}$ Calhoun (1992) comenta desde diversos ángulos os estreitos vencellos que existen entre a aparición das esferas públicas e o nacionalismo. 
non só trouxo consigo a aparición de novas opcións de participación política, senón tamén a consolidación dun marco discursivo común baseado na lóxica homoxeneizadora do estado-nación, entre a cal e a diversidade sociocultural xorde tensión. $\mathrm{Na}$ medida en que esa diversidade se resistía á asimilación, as narrativas públicas «oficiais» que vinculaban democracia e nación chocaban coas posturas contrarias que denunciaban as estratexias hexemónicas subxacentes á integración nacional. Malia que esa asociación chegou a revestir un carácter particularmente virulento entre os «tardíos» nacionalizadores da Europa oriental, de ningún modo está ausente da Europa occidental, como exemplifican os casos de Bélxica, o Reino Unido e España (Cederman e Kraus 2005: 293-7).

Con todo, no noso imaxinario colectivo tendemos a abstraernos dos aspectos máis molestos da historia da democracia, dos estados-nación e da integración cultural en Europa. Como nos formamos en contornas cognitivas modeladas en boa medida polo nacionalismo metodolóxico, non cuestionamos o que nos amosan os mapas políticos de Europa ao lles asignaren unha cor, un nome e atributos culturais a entidades políticas discretas. $\mathrm{O}$ mesmo pode dicirse do encadramento institucional das identidades lingüísticas: desde a perspectiva europea que constitúe a norma, a Norma con maiúscula é a da maioría, e, así, un non ten a idea de que un cidadán sueco pode falar sami, un español éuscaro ou un romanés húngaro, porque a identidade dese cidadán se vincula a un estado-nación, e o que consideramos que é a Lingua da Nación (con maiúscula) e dos «seus» cidadáns é a lingua maioritaria.

No noso modo habitual de entender a política democrática — política feita nun só país e nunha soa lingua-, a perspectiva oficial non só se tornou omnipresente, senón que alén diso pasou a ser o modelo padrón co que os expertos en ciencias sociais avalían a integración política. As nocións que temos do desenvolvemento político baséanse nunha secuencia histórica ideal e típica, na cal a configuración do Estado e a racionalización das estruturas gobernamentais preparan o camiño para que se forme unha esfera pública da que se deriva unha presión que obriga o goberno a lexitimar as súas decisións baseándose en razóns democráticas. Ante este modelo case que paradigmático, damos por feito que a cuestión da lingua que empregamos para comunicármonos na esfera pública, que non é outra cousa que a lingua da democracia, quedou "resolta» no proceso da formación do Estado, é dicir, antes de que o público democrático come- 
zase a desempeñar a función que lle corresponde. Ao mesmo tempo, existe unha corrente que goza de grande influencia na teoría política normativa, que se remonta a John Stuart Mill (1972: 391-398) e que na actualidade ten un sobranceiro defensor na figura de Jürgen Habermas (2001: 116-124), corrente que sostén que o potencial de deliberación que ten un público democrático depende da existencia dunha lingua común na cal aqueles que constitúen ese público poidan exporlles as súas preocupacións aos demais, pois — segue a argumentación - sen un medio lingüístico compartido non nace unha cultura política común, o cal comporta unha segmentación do espazo da comunicación política que bloquea a formación dunha esfera pública democrática. En termos xerais, tanto as avaliacións empíricas das bases comunicativas sobre as que se erguen as democracias modernas como as consideracións normativas referidas aos elementos que se precisan para crear unha política democrática lexítima tenden a converxer na noción de que a democracia é democracia nunha soa lingua.

\section{MINORÍAS, RECOÑECEMENTO E DIGLOSIA}

Á derradeira, que é o que pode ter de malo o Estado "glotófago»? Por que, en todo caso, se rexeita a asimilación lingüística? Por que sobreviven as linguas minoritarias? Por que os membros das minorías lingüísticas están dispostos a facer grandes sacrificios persoais á hora de defenderen o seu idioma? En que sentido é importante preservar unha identidade lingüistica particular? Ou, por dicilo aínda máis ás claras, onde estaría o problema se todos nos erguésemos mañá falando o mesmo idioma (probablemente inglés) e así se recrease o mundo tal e como era antes de Babel?

Para abordarmos estes problemas desde o ángulo da política da lingua temos que tomar como punto de partida o feito de que a cuestión da diversidade ocupa un lugar central en todos os intentos de elaboración dunha teoría da democracia que estea á altura dos tempos 5 . Poucos temas recibiron tanta atención nos últimos debates normativos referidos á cuestión de como artellar formas de goberno lexítimas nunhas sociedades cada vez máis heteroxéneas e complexas; e unha das liñas deses

${ }^{5}$ A exposición que segue está baseada en Kraus (2008: 78-105). 
debates, de grande influencia na argumentación que aquí presentamos, considera que o recoñecemento constitúe unha categoría fundamental na reconciliación da diversidade cultural e a cidadanía democrática. Porén, os filósofos e os teóricos políticos tenden a falar da política do recoñecemento cun alto grao de abstracción, cando resulta que, para entendermos mellor os vencellos que existen entre a diversidade e o recoñecemento, temos que basearnos nunha teoría política da lingua que lles preste especial atención aos aspectos das identidades e os repertorios lingüísticos. Así, desde o punto de vista expresivo, o idioma ten un gran peso no modo en que unha comunidade «se entende» (nun sentido certamente literal) a si propia e aos seus membros, e o recoñecemento das identidades lingüísticas contribúe substancialmente a protexer as liberdades individuais, xa que ratifica no ámbito institucional as relacións que existen entre a lingua como vencello social e a lingua como fonte de autoestima.

Desde a perspectiva de Herder e Humboldt, que destacaron o compoñente social da dimensión expresiva da lingua, esta é a chave que permite comprender a humanidade como unida na diferenciación: por unha banda, a lingua considérase un recurso do que se derivan autonomía e liberdade para o ser humano e, pola outra, tal autonomía está inserida nun contexto social e relaciónase coas prácticas colectivas dunha comunidade lingüística, co cal a lingua crea un vínculo social elemental. En certo sentido, pois, un acto de fala individual sempre se refire a unha comunidade de falantes e, ao mesmo tempo, á derradeira é a propia lingua a que define e sostén esa comunidade. Wilhelm von Humboldt (1963 [1830]: 414-439) recorre á imaxe dunha rede — Gewebe - para describir o xeito en que a lingua é á vez suxeito e obxecto de conformación da comunicación humana.

É evidente a relevancia política que reviste o que pode denominarse dimensión instrumental da lingua: temos que ser quen capaces de empregar a lingua de conformidade co que funcionalmente esixan diversas situacións particulares en toda clase de contextos cotiáns, e as nosas posibilidades vitais, para se cumpriren, dependen en boa medida da nosa competencia lingüística. Por outro lado, como a aprendizaxe dun idioma supón uns custos, o dereito a empregarmos a nosa lingua materna en tantos eidos como for posible ten carácter instrumental. Mais é a dimensión expresiva a que torna politicamente significativo un idioma, trazo que adoita mesturarse coas demandas de «recoñecemento». A lingua é un 
recurso que precisamos para a comunicación individual e, ao adquirírmolo, vinculámonos cunha comunidade dada que está definida culturalmente. Se, segundo as liñas do razoamento que vai desde Herder e Humboldt ata Taylor, pasando por Wittgenstein, un idioma forma unha rede social irredutible, para gañar a posibilidade de acceder ao desenvolvemento e á liberdade individual cómpre un apoio colectivo que, na política moderna, ha de traducirse en disposicións institucionais destinadas a reproducir esa rede. Xa que logo, se se pretende respectar a dignidade dos individuos, haberá que recoñecer ademais nun grao satisfactorio a identidade lingüística e cultural da súa comunidade de orixe (Taylor 1992). Cando, no eido institucional, se pasan por alto, se negan ou mesmo se reprimen as bases culturais sobre as que se ergue o noso desenvolvemento persoal e que xulgamos auténticas, tamén se lle poñen graves pexas á nosa autoestima, un ben que ten unha gran relevancia no proceso de construírmos e protexermos a nosa autonomía individual.

Hai cousa de trinta anos fíxose un estudo comparativo pioneiro no que se abordaban as causas e as implicacións políticas do «renacemento étnico» experimentado polas sociedades modernas e industrializadas da Europa occidental. Nese estudo, que segue a ser unha lectura sumamente recomendable, o sociólogo político finés Erik Allardt, logo de analizar unha ampla mostra de casos empíricos, mantén que a mobilización das minorías lingüísticas territoriais do Occidente desenvolvido non pode interpretarse —ou, en todo caso, xa non debería- como reacción contra uns tipos de discriminación que se asocian coa exclusión social e comportan serias consecuencias. A diferenza do que ocorría coas etnias constituídas por inmigrantes, na maioría dos casos as minorías lingüísticas «autóctonas» de Europa non loitaban por superar unha situación de subordinación social e económica directa, senón que a súa batalla se encamiñaba ao recoñecemento — como maxistralmente o expresou Allardt (1979: 43-47) nunha análise que abriu novos vieiros—e, así, anticipábanse ao que hoxe é un tema de debate fundamental na teoría política. Desde o punto de vista deste autor, ao presentaren estas demandas de recoñecemento, o obxectivo principal das minorías era que as maiorías aceptasen a categorización que as primeiras establecían para si. Ata os nosos días, esta autocategorización, no sentir da meirande parte dos grupos minoritarios en cuestión, non ten a súa verdadeira base en condicións socioeconómicas subxacentes, senón que, en última instancia, o seu cerne consiste nunha identidade cultural distintiva cuxo principal símbolo é a lingua. 
En concreto, os grupos que gozan dunha capacidade de mobilización política relativamente grande - como os tiroleses en Italia, os vascos e os cataláns en España, os valóns e os flamengos en Bélxica ou os fineses falantes de sueco- non resultan suficientemente caracterizados atribuíndolles unha posición inferior na división cultural do traballo, pois o obxectivo da súa loita é o establecemento de condicións políticas e institucionais que lles permitan reproducir unha identidade colectiva que eles consideran particular e que impidan que sexan asimilados na maioría. Falamos de grupos que están expostos a unha peculiar dialéctica de igualdade socioeconómica e diferenciación cultural. Simplificando as cousas, podemos concluír que os maiores problemas que figuran entre os temas que teñen de abordar as políticas lingüísticas da Europa de hoxe non se refiren tanto a cuestións de categoría material como ao respecto por un mesmo e á «honra».

Á luz do que quedou patente nas últimas décadas, resulta aínda máis persuasiva a interpretación que fai Allardt das loitas polo recoñecemento lingüístico: con certeza, a forza acadada a escala internacional polas "políticas da identidade» amosa que a decisión de rexeitar a asimilación constitúe un factor tan pertinente na dinámica da mobilización política como o é a vontade de superar a exclusión social e a inxustiza económica. Se levamos ao eido da teoría política o que aprendemos da perspectiva sociolóxica política que aplica Allardt, podemos concluír que, nun escenario democrático, a autocategorización é, nun sentido elemental, un primeiro paso fundamental para exercer a autodeterminación, afirmación que resulta válida tanto á escala do individuo como á do grupo. Máis aínda, conecta os dous niveis, e esta conexión resulta particularmente evidente cando se trata da lingua, dado que para establecer unha autocategorización lingüística cómpre que existan categorías plausibles, é dicir, categorías que, inevitablemente, vaian ligadas a comunidades lingüísticas reais. A identidade lingüística que podemos adoptar canto individuos sempre se relaciona cun universo simbólico de creación social (e, en consecuencia, colectiva). Na lingua temos un óptimo exemplo de onde se sitúan a liberdade e a creatividade das que gozamos como individuos, inseridas como están nun contexto cultural que vén conformado polas prácticas colectivas. Esta posición tórnase especialmente relevante cando se trata da liberdade política, pois, en efecto, para desenvolver as nosas capacidades como cidadáns temos de actuar canda os demais e recorrer con moita frecuencia a habilidades comunicativas lingüísticas (e tamén extralin- 
güísticas); e é evidente, xaora, que a adquisición destas destrezas depende dos vínculos culturais e sociais. Endebén, con respecto á lingua, tomar en serio a posición da que falabamos implica respectar e protexer a diversidade lingüística. Para pór un exemplo concreto: o dereito á liberdade de expresión dos membros dunha minoría lingüística non se pode limitar ao dereito de comunicárense libremente na lingua maioritaria, senón que tamén debe incluír o dereito de adquiriren e usaren cando queiran a fala da minoría. Dun xeito semellante, o recoñecemento lingüístico ha de aspirar, así mesmo, a aliviar a carga que teñen que levar os membros dos grupos minoritarios en comparanza con aqueles que pertencen a unha maioría, para permitir que os primeiros sexan igualmente libres. Por norma xeral, dáse por feito que os individuos das minorías deben adquirir un repertorio plurilingüe (que abranga tanto a lingua non dominante como a dominante), mentres que os da maioría non teñen grandes problemas se recorren exclusivamente a esta última nas súas interaccións cotiás.

Recapitular a descrición que fai Allardt da mobilización das minorías lingüísticas da Europa occidental segue a ser unha tarefa instrutiva que nos permite abordar unha serie de importantes problemas políticos que comporta nestes tempos a diversidade cultural e lingüística da Unión Europea. Se queremos chegar a comprender polo miúdo as estruturas de conflito que caracterizan os contextos plurilingües, temos que estar dispostos a dar un paso máis, un paso de gran significación, que consiste en establecer unha relación entre a función que desempeña o recoñecemento nas políticas lingüísticas e unha destacada tradición de investigación en sociolingüística que se centra no estudo da diglosia (Fishman 1967). Este concepto fai referencia a contextos lingüísticos en que dúas ou mais linguas ocupan dominios funcionais claramente separados no seo da mesma sociedade; e, máis aínda, esta diferenza funcional xeralmente coincide cunha xerarquía social: así, é habitual que nesta xerarquía se distinga unha lingua «elevada», empregada nos eidos do ensino, a Administración, as finanzas e os medios de comunicación, fronte a unha lingua «baixa». O bilingüismo social e a diglosia combínanse de diversos xeitos, como amosa Fishman (1971: 286-288), e a súa correlación é un espello da dinámica da mudanza social e política. Ata agora a experiencia histórica semella indicar que para que dúas (ou máis) linguas poidan coexistir nun mesmo territorio en pé de igualdade é preciso realizar grandes esforzos a escala institucional co fin de evitar a aparición de 
conflitos politicamente virulentos referidos ao status desas linguas (é dicir, loitas por un recoñecemento fundamentado na súa igual dignidade). Como se ten observado (Laponce 1987: 33-42), o bilingüismo social sen diglosia tende a ser intrinsecamente inestable e, de certo, en contornas metropolitanas oficialmente bilingües, como Montreal, Bruxelas ou Barcelona, óense de xeito reiterado queixas referidas a que os custos de adquirir e manter un repertorio comunicativo bilingüe non se reparten por igual entre os diferentes grupos lingüísticos, polo que o bilingüismo acaba por resultar asimétrico.

Tocante ás teorías do recoñecemento, o concepto de diglosia constitúe unha importante achega á nosa maneira de entender o conflito lingüístico nas democracias occidentais. En efecto, as demandas de recoñecemento que se presentan no terreo da política lingüística son, en boa medida, demandas que se efectúan para atenuar, ou por veces mesmo superar, os efectos da diglosia e, ao se mobilizaren a prol da igualdade lingüística, os membros dos grupos que se ven expostos a uns contextos institucionais diglósicos buscan ampliar o abano de dominios sociais e funcionais en que teñen a posibilidade de empregar a súa lingua vernácula. Así, pois, o recoñecemento lingüístico implica que aos individuos que pertencen a un grupo minoritario se lles conceda a opción de levaren unha existencia cotiá que non diste moito da «normalidade» comunicativa á que están afeitos os membros da cultura dominante. Neste contexto, é revelador que as asimetrías que se presentan nos repertorios bilingües resulten especialmente problemáticas en grupos cuxos membros viven as situacións de diglosia como situacións de desaxuste entre distintas categorías sociais. A este respecto, a revolta iniciada en Bélxica hai unhas décadas por membros da emerxente clase media falante de neerlandés contra o dominio do francés constitúe un exemplo certamente paradigmático.

Para moitos a lingua é a chave de acceso ao eido da autenticidade, un emblema da identidade colectiva ao que non se debe renunciar de ningún xeito, e, en consecuencia, en contextos socioculturais caracterizados pola existencia de diglosia, as loitas polo recoñecemento adoitan levar consigo un conflito sobre a categoría das linguas. Moi a miúdo, as medidas destinadas a igualar o status das linguas existentes no seo dun país contribúen a eliminar os vellos resentimentos que albergan os falantes da variedade lingüística que antes ocupaba unha posición inferior, mais tamén crean outros que afectan aos membros da comunidade lingüística que anteriormente se asociaba cunha categoría superior. Polo 
tanto, unha política lingüística de base democrática ha de ter como obxecto a superación do resentimento colectivo para así fomentar a integración de diferentes grupos culturais nun marco institucional común, e tomarmos en serio este obxectivo implica sermos conscientes dos múltiples retos que comporta.

\section{OS EFECTOS DA EUROPEIZACIÓN}

O concepto de europeización, tal e como o emprego eu aquí, presenta dúas dimensións fundamentais: por unha banda, refírese ás diversas competencias reguladoras que hoxe están nas mans das institucións da Unión Europea (UE) ou se comparten entre esta e os estados membros; por outra banda, pretende reflectir a interiorización da dimensión europea por parte de moitos outros protagonistas de niveis políticos diferentes. $\mathrm{O}$ actual proceso de Boloña constitúe un bo exemplo a este respecto: malia o ensino non ser competencia da Unión, os estados membros non por iso deixan de facer un esforzo considerable por definiren criterios comúns para a formación universitaria. Dadas estas características, cales son os efectos da europeización nas cuestións referidas á lingua e á identidade lingüística?

A este respecto, o panorama ao que nos enfrontamos é complexo porque a europeización non é un proceso homoxéneo e unidireccional, senón un fenómeno cheo de tensións e contradicións. Antes de máis nada, permítanme abreviar moito e aseverar simplemente que é certo que a integración europea comporta unha dinámica política que transcende o ámbito nacional, mais simultaneamente tamén é verdade que os protagonistas do xogo europeizador seguen a ser gobernos nacionais que representan os intereses de estados-nación.

O respecto pola diversidade -que, no contexto institucional da Unión, ha de entenderse sobre todo como diversidade lingüística- desempeña unha función sobranceira no discurso político oficial de Europa. Así, por unha banda, confíase en que o recoñecemento da diversidade cultural sirva de medida de protección normativa contra a potencial aparición de pretensións hexemónicas no seo da UE, as cales poderían desembocar en conflitos que atrancasen o proxecto de integración. Por outra banda, a sensibilidade intercultural que a UE afirma manifestar ao tratar a cuestión da diversidade, que ten a súa expresión máis salientble na adopción do pluri- 
lingüismo, adoita presentarse como vantaxe normativa cando se compara Europa con outros polos mundiais de integración rexional.

Con todo, a «política do recoñecemento» que practica Europa non está exenta de incongruencias significativas. Para empezar, ese recoñecemento está nesgado a prol das identidades que encarnan os estados-nación; os patróns de identificación subnacionais, transnacionais ou interculturais e «híbridos» desempeñan un papel claramente subordinado na perspectiva institucional que adopta a Unión ao se enfrontar á diversidade, pois o recoñecemento e a protección da diversidade cultural da UE van dirixidos principalmente a aquelas identidades culturais que veñen encarnadas polas institucións dos estados-nación. Unha consecuencia desta situación consiste en que a presión que se exerce para o recoñecemento das minorías é especialmente intensa cando a condición destas constitúe un problema para as relacións interestatais en Europa. Aínda que á protección ás minorías e, en particular, á concesión de dereitos ás minorías lingüísticas, se lles outorgou unha importancia fundamental nas sucesivas adhesións á UE de países da zona de Europa central e do leste, o seu peso é moito menos significativo no tocante á supervisión mutua dos estados membros máis veteranos da Unión. Outro bo exemplo constitúeo, no mesmo contexto, o réxime lingüístico que se aplica nas institucións comunitarias: oficialmente concédeselles igual condición a todas as linguas existentes nun Estado, con independencia de criterios demográficos, económicos ou sociolingüísticos, mais esa igualdade só se aplica ás linguas de Estado. Consecuentemente, os falantes de maltés (arredor de 340 000) ou estoniano (1 000 000) gozan dunha posición privilexiada en comparación cos membros de comunidades lingüísticas como a galesa (500 000) ou a catalá (7 000 000), cuxas linguas teñen a condición de oficiais nos seus respectivos territorios (polo menos, nunha gran parte), a pesar do cal non son as linguas de Estado.

Debido ao nesgo estatístico que afecta ao recoñecemento da diversidade, as identidades culturais adoitan entrar no escenario político en canto ferramentas tácticas e empréganse principalmente para sustentar a articulación dos intereses dos estados-nación nun sistema de arduas e prolongadas negociacións intergobernamentais. Deste xeito, as políticas da identidade entran en escena en calidade de substituto subliminal de algo que noutro caso sería considerado política dos intereses nacionais pura e dura, crítica que se expresou a propósito dos chamamentos franceses para defender a exception culturelle no eido das políticas do audiovisual, por exemplo. En 
última instancia, as institucións comunitarias parecen entaladas no dilema que supón atopar un equilibrio entre a protección da diversidade e a creación dun marco común de comunicación política para os cidadáns europeos. Xa pasaron máis de cincuenta anos desde o Tratado de Roma, mais a UE segue a eludir un debate político concienciudo sobre o que debería significar hoxe a xustiza lingüística en Europa. Para abordar a cuestión das linguas comunitarias faría falta tratar de darlle unha resposta directa á pregunta de como procesar institucionalmente e dun xeito reflexivo o plurilingüismo dos organismos europeos, así como na comunicación que se establece entre estas institucións e os cidadáns.

Por moito que se invoque reiterada e retoricamente o principio da unidade na diversidade, este mesmo debate estivo e está ausente da axenda de temas para tratar na política comunitaria ${ }^{6}$.

Nestes momentos, talvez o trazo máis característico da perspectiva da UE sobre o recoñecemento da diversidade lingüística radique nas súas múltiples contradicións. En efecto, tanto no eido da lingua como no cultural, por vía da regra resulta problemático que as institucións da UE recoñezan a diversidade e que se declare nelas a súa existencia, como demostra a presenza dun marcado favoritismo polas identidades que encarnan os estados-nación en detrimento das non dominantes e «minorizadas». Máis aínda, no réxime de cidadanía transnacional que establece a lexislación europea diferénciase con nitidez entre minorías «vellas» e «novas», así como entre emigrantes intraeuropeos e extraeuropeos: canto máis emigrante e máis extraeuropea sexa unha persoa, máis limitados resultarán ser os seus dereitos culturais ante as autoridades europeas e nacionais?.

Aínda hai que mencionar un factor importante que engade máis complexidade a este panorama: a silandeira pero potente irrupción do inglés como lingua franca europea de facto. É dicir, Boloña fala inglés. É evidente que este proceso ten múltiples e fondas implicacións para todas as comunidades lingüísticas de Europa, das que

${ }^{6}$ En Kraus (2008: 111-138) e Phillipson (2003: 105-138) preséntanse unha serie de avaliacións críticas da política lingüística institucional da Unión Europea.

${ }^{7}$ En datas recentes o goberno turco tentou poñer en dúbida esta diferenciación nas súas relacións bilaterais con Alemaña e afirmou que habería que concederlles aos «turcos alemáns» dereitos semellantes aos que se lles recoñecen tipicamente ás minorías nacionais e, así, establecer para eles un sistema escolar e universitario de seu. Véxase o artigo do Spiegel Online «Erdogan fordert türkische Gymnasien und Universitäten in Deutschland» (8 de febreiro de 2008), <http://www.spiegel.de/politik/deutschland/ $0,1518,534052,00 . h$ tml $>$. 
vou apuntar brevemente dúas. Para empezar, o avance imparable como parece agora- do inglés como vehículo principal da comunicación transeuropea constitúe unha ameaza manifesta para a hexemonía das linguas nacionais por todo o continente, dado que fai que se xeneralicen as presións diglósicas e se puxe con forza cara ao plurilingüismo. En estados-nación europeos de maior tamaño, como Francia, Alemaña, España e Italia, a mudanza pode alcanzar proporcións descomunais e, por conseguinte, están abrollando as conxecturas referidas a unha transformación do mapa sociolingüístico de Europa nunha dirección que pode levarnos de volta a unha situación que teña moitos puntos en común coa época anterior ao nacionalismo. Aínda que talvez esta sexa unha interpretación algo simplista do que está por vir, xa que as linguas nacionais gozan de arraigamento institucional e non van ceder os seus bastións sen se arrepoñer.

Ao mesmo tempo, o avance do inglés europeo, por moi crítico que sexa o noso exame das razóns que o motivan, non segue a lóxica da imposición política (Van Parijs 2004), senón que vai transformando sen balbordo a relación que existe entre capas previas de diversidade lingüística, entre maiorías e minorías lingüísticas, xa que fai que se forme o que poderiamos denominar unha «supermaioría» que abrangue os membros de todos os demais grupos lingüísticos. Desde a perspectiva que fun presentando aquí, unha pregunta fundamental é a de se esta transformación vai conducir á aparición de novos xeitos de vivir e artellar a autenticidade, cousa que, en última instancia, levaría a considerar o recoñecemento desde outros puntos de vista. En termos xerais, semella que por agora os membros dos grupos lingüísticos minoritarios están menos preocupados polo auxe do inglés ca aqueles que manifestan a súa adhesión a linguas nacionais antes moi arraigadas (do cal o caso paradigmático, a este respecto, probablemente sexa o francés). Coido que deberiamos evitar tratar con moito simplismo a dinámica deste problema. Con todo, hai que dicir que, desde a perspectiva das minorías, poida que haxa polo menos unha razón para sermos moderadamente optimistas: se a europeización non significa anglización sen máis, senón un aumento significativo dos repertorios plurilingües da Europa continental, se cadra á derradeira fai que aumente a concienciación ante a importancia da identidade lingüística tamén entre os membros das maiorías —ou debería dicir «do que antes eran maiorías»— e, deste xeito, contribúa a que se entendan as preocupacións das minorías. 


\section{BIBLIOGRAFÍA}

Allardt, E.: Implications of the Ethnic Revival in Modern, Industrialized Society. A Comparative Study of the Linguistic Minorities in Western Europe, Helsinki, Societas Scientiarum Fennica (Commentationes Scientiarum Socialium 12), 1979.

Anderson, B.: Imagined Communities: Reflections on the Origin and Spread of Nationalism [ed. rev.], Londres, Verso, 1991.

BILlig, M.: Banal Nationalism, Londres, Sage, 1995.

Burke, P.: Languages and Communities in Early Modern Europe, Cambridge, Cambridge University Press, 2004.

Calhoun, C. (ed.): Habermas and the Public Sphere, Cambridge, MA, Mit Press, 1992.

Cederman, L.-E. e P. A. Kraus: "Transnational Communication and the European Demos", en R. LATHAM e S. SASSEN (eds.), Digital Formations: Information Technology and New Architectures in the Global Realm, Princeton, NJ, Princeton University Press, 2005, pp. 283-311.

Coulmas, F.: Sprache und Staat: Studien zur Sprachplanung und Sprachpolitik, Berlín, de Gruyter, 1985.

Deutsch, K. W.: Nationalism and Social Communication, Cambridge, MA, MIT Press, 1966.

Eisenstadt, S. N.: Fundamentalism, Sectarianism and Revolution: The Jacobin Dimensions of Modernity, Cambridge, Cambridge University Press, 1999.

Fishman, J. A.: «Bilingualism With and Without Diglossia; Diglossia With and Without Bilingualism», Journal of Social Issues, 23, 1967, pp. 29-38.

— "The Sociology of Language: An Interdisciplinary Social Science Approach to Language in Society», en J. A. Fishman (ed.), Advances in the Sociology of Language, Vol. I, The Hague, Mouton, 1971, pp. $217-$ -404 .

Giddens, A.: The Nation-State and Violence, Cambridge, Polity Press, 1985.

HABERMAS, J.: Strukturwandel der Öffentlichkeit: Untersuchungen zu einer Kategorie der bürgerlichen Gesellschaft [nova ed.], Frankfurt am Main, Suhrkamp, 1990 [1962].

—Zeit der Übergänge, Frankfurt am Main, Suhrkamp, 2001.

Hogan-Brun, G.; C. Mar-Molinero e P. STEVEnson (eds.): Discourses on Language and Integration; Amsterdam, John Benjamins, 2009.

Hroch, M.: Social Preconditions of National Revival in Europe: A Comparative Analysis of Patriotic Groups among the Smaller European Nations, Cambridge, Cambridge University Press, 1985.

HumboldT, W. von: «Ueber die Verschiedenheit des menschlichen Sprachbaues und ihren Einfluss auf die geistige Entwicklung des Menschengeschlechts», en W. vON HumBOLDT, Werke in fünf Bänden, III, Schriften zur Sprachphilosophie, Berlín, Rütten \& Loening, 1963 [1830-1835], pp. 368-756.

Jacob, J. E. e D. C. Gordon: «Language Policy in France», en W. R. Beer e J. E. Jacob (eds.), Language Policy and National Unity, Totowa, NJ, Rowman \& Allanheld, 1985, pp. 106-133.

KraUs, P. A.: A Union of Diversity: Language, Identity and Polity-Building in Europe, Cambridge, Cambridge University Press, 2008.

LAPONCE, J. A.: Languages and Their Territories, Toronto, University of Toronto Press, 1987.

MAAS, U.: Sprachpolitik und politische Sprachwissenschaft, Frankfurt am Main, Suhrkamp, 1989.

Mann, M.: The Dark Side of Democracy: Explaining Ethnic Cleansing, Nova York, Cambridge University Press, 2005. 
Peter A. Kraus

Mill, J. S.: «Considerations on Representative Government», en J. S. MiLl, Utilitarianism. Liberty. Representative Government (ed. Harry Burrows Acton), Londres, Dent, 1972 [1861], pp. 187-428.

PARIJS, Ph. van : «Europe’s Linguistic Challenge», Archives Européennes de Sociologie, XLV, 2004, pp. 113-154.

Phillipson, R.: English-Only Europe? Challenging Language Policy, Londres, Routledge, 2003.

RoKKan, S.: State Formation, Nation-Building, and Mass Politics in Europe, Nova York, Oxford University Press, 1999.

SASSEN, S.: Territory, Authority, Rights: From Medieval to Global Assemblages, Princeton, NJ, Princeton University Press, 2006.

TAYLOR, Ch.: Multiculturalism and "The Politics of Recognition», Princeton, NJ, Princeton University Press, 1992.

Weber, M.: Wirtschaft und Gesellschaft, Tübingen, Mohr, 1980 [1922]. 